\title{
Primary Hyperoxaluria in Korean Pediatric Patients
}

\author{
Yunsoo Choe, M.D. ${ }^{1 *}$ \\ Jiwon M. Lee, M.D., Ph.D. ${ }^{2 *}$ \\ Ji Hyun Kim, M.D., M.S. ${ }^{1}$ \\ Myung Hyun Cho, M.D., M.S. ${ }^{1}$ \\ Seong Heon Kim, M.D., Ph.D. ${ }^{3}$ \\ Joo Hoon Lee, M.D., Ph.D. ${ }^{4}$ \\ Young Seo Park, M.D., Ph.D. ${ }^{4}$ \\ Hee Gyung Kang, M.D., Ph.D. ${ }^{1}$ \\ II Soo Ha, M.D., Ph.D. ${ }^{1,5}$ \\ Hae Il Cheong, M.D., Ph.D. ${ }^{1,5}$
}

Department of Pediatrics' ${ }^{1}$, Seoul National University Children's Hospital, Seoul, Korea, Department of Pediatrics ${ }^{2}$, Chungnam National University Children's Hospital, Daejeon, Korea, Department of Pediatrics ${ }^{3}$, Pusan National University Children's Hospital, Yangsan, Korea, Department of Pediatrics ${ }^{4}$, Asan Medical Center, Seoul, Korea, Kidney Research Institute ${ }^{5}$, Medical Research Center, Seoul National University College of Medicine, Seoul, Korea

*These authors contributed equally to this work.

Corresponding author:

Haell Cheong, M.D., Ph.D.

Department of Pediatrics, Seoul National University Children's Hospital 101 Daehang-

no, Jongno-Gu, Seoul 03080, Korea

Tel: $+82-2-2072-2810$

Fax: +82-2-743-3455

E-mail:cheonghi@snu.ac.kr

Received: 17 July 2019

Revised: 21 September 2019

Accepted: 4 October 2019

This is an open-access article distributed under the terms of the Creative Commons Attribution Non-Commercial License (http:// creativecommons.org/licenses/by-nc/4.0/) which permits unrestricted non-commercial use, distribution, and reproduction in any medium, provided the original work is properly cited.

Copyright (C) 2019 The Korean Society of Pediatric Nephrology
Background: Primary hyperoxaluria (PH), a rare inborn error of glyoxylate meta bolism causing overproduction of oxalate, is classified into three genetic subgroups: type 1-3 (PH1-PH3) caused by AGXT, GRHPR, and HOGA 1 gene mutations, respectively. We performed a retrospective case series study of Korean pediatric patients with $\mathrm{PH}$.

Methods: In total, 11 unrelated pediatric patients were recruited and their phenotypes and genotypes were analyzed by a retrospective review of their medical records.

Results: Mutational analyses revealed biallelic $A G X T$ mutations (PH1) in nine patients and a single heterozygous GRHPR and HOGA1 mutation in one patient each. The c.33dupC was the most common $A G X T$ mutation with an allelic frequency of $44 \%$. The median age of onset was 3 months (range, 2 months -3 years), and eight patients with $\mathrm{PH} 1$ presented with end stage renal disease (ESRD). Patients with two truncating mutations showed an earlier age of onset and more frequent retinal involvement than patients with one truncating mutation. Among eight $\mathrm{PH} 1$ patients presenting with ESRD, five patients were treated with intensive dialysis followed by liver transplantation $(n=5)$ with/without subsequent kidney transplantation $(\mathrm{n}=3)$.

Conclusion: Most patients presented with severe infantile forms of PH. Patients with two truncating mutations displayed more severe phenotypes than those of patients with one truncating mutation. Sequential liver and kidney transplantation was adopted for $\mathrm{PH} 1$ patients presenting with ESRD. A larger nation-wide multicenter study is needed to confirm the genotype-phenotype correlations and outcomes of organ transplantation.

Key words: Primary hyperoxaluria, $A G X T$ gene, End stage renal disease, Genotype-phenotype correlation, Liver transplantation, Kidney transplantation

\section{Introduction}

Primary hyperoxaluria $(\mathrm{PH})$ is a rare autosomal recessive inborn error of glyoxylate metabolism that results in endogenous overproduction of oxalate ${ }^{1)}$. $\mathrm{PH}$ is a genetically and clinically heterogeneous disease and is classified into three subgroups.

PH type 1 (PH1), the most frequent and severe subgroup accounting for the majority of cases, is caused by mutations in $A G X T$, which encodes the peroxisomal liver-specific enzyme alanine-glyoxylate aminotransferase (AGT). ${ }^{2)}$ AGT catalyzes the conversion of glyoxylate to glycine. Defective function of AGT results in conversion of glyoxylate to oxalate, which accumulates in the 
kidneys and other organs by forming insoluble calcium oxalate salts. Progressive renal deposition of calcium oxalate results in urolithiasis and/or nephrocalcinosis, followed by renal failure. Excessive blood levels of oxalate may lead to systemic oxalosis with oxalate deposition predominantly in the bone, skin, retina, myocardium, vessel walls, and the central nervous system. PH type 2 (PH2) is caused by mutations in GRHPR, which encodes glyoxylate reductasehydroxypyruvate reductase (GRHPR) ${ }^{3}$. GRHPR catalyzes the reduction of glyoxylate to glycolate. Functional deficiency of GRHPR results in abnormally increased metabolism of glyoxylate to oxalate by lactate dehydrogenase. $\mathrm{PH}$ type 3 (PH3) is caused by mutations in HOGA1, which encodes the liver-specific mitochondrial enzyme 4-hydroxy2-oxoglutarate aldolase $(\mathrm{HOGA})^{4)}$. It is unclear why defective HOGA causes oxalate accumulation.

Combined liver and kidney transplantation is the treatment of choice in patients with PH1, whereas isolated kidney transplantation is recommended for patients with $\mathrm{PH}$ 2. Neither kidney nor liver transplantation is required in patients with $\mathrm{PH} 3$, as none of the patients with $\mathrm{PH} 3$ have been reported to develop end-stage renal disease $(\mathrm{ESRD})^{5)}$

Although there have been several case reports of $\mathrm{PH}$ in Korea $^{6,7)}$, systematic studies have not been reported yet. Herein we report 11 cases of Korean patients with $\mathrm{PH}$, with retrospective analyses of genotype-phenotype correlations and the outcome of combined liver and kidney transplantation in five patients.

\section{Materials and methods}

In total, 11 pediatric patients who were diagnosed with PH during the period from December 2008 to July 2018 at three tertiary care centers (Seoul National University Children's Hospital Seoul, Korea, Asan Medical Center, Seoul, Korea, and Pusan University Children's Hospital, Yangsan, Korea) were recruited. All patients were non-consanguineous Koreans, except for one patient (Patient 8) who had a Korean mother and Taiwanese father. Diagnosis of PH was based on increased urinary excretion levels of oxalate ${ }^{5}$ and/or presence of genetic mutations in one of the three candidate genes, i.e., $A G X T$ for $\mathrm{PH} 1, G R H P R$ for $\mathrm{PH} 2$, and
HOGA1 for PH3. Genomic DNAs of the patients and their available family members were isolated from their peripheral blood leukocytes. Entire coding regions of the three genes were amplified via polymerase chain reaction and sequenced directly. All the primers for polymerase chain reaction were designed to start from intronic sequences, and the primer sequences are available upon request.

\section{Ethics statement}

This study was approved by the Institutional Review Board of Seoul National University Hospital (IRB No. 0812-002-264). The patients and/or their parents provided informed consent to participate in this study.

\section{Results}

\section{Genotypes}

Mutational analyses revealed compound heterozygous or homozygous mutations in $A G X T$ in nine patients. The remaining two patients carried a single heterozygous mutation in GRHPR and HOGA1, respectively. Among 10 different $A G X T$ mutations, 6 were truncating mutations. The c.33dupC mutation in $A G X T$ was common with an allele frequency of $8 / 18$ (44.4\%) (Table 1).

\section{Phenotypes}

The clinical features and disease courses of the patients are summarized in Table 2. Among 11 patients in this study, 10 patients were boys and one patient with $A G X T$ mutation was a girl. The median age of onset was 3 months (range, 2 months -3 years), and eight patients developed renal symptoms at the age of 5 months or younger. Eight patients with PH1 already had ESRD at initial presentation, and three patients presented with nephrolithiasis with/without gross hematuria. A family history of renal diseases was positive in two patients: Patient 7 had a grand-uncle who had ESRD of unknown causes, and Patient 9 had a grand-uncle who had an episode of spontaneous passage of a urinary stone. Urinary oxalate excretion levels were higher in two non$\mathrm{PH} 1$ patients than in patients with $\mathrm{PH} 1$. This difference may be caused by different renal functions between both groups of patients. Nephrocalcinosis was detected in all patients on kidney ultrasonography and/or CT scan., ex- 
cept for Patient 9 who presented with nephrolithiasis, and nephrolithiasis was accompanied in five patients (Fig.1). Six patients with PH1 had retinal involvement (Fig.2), indicating systemic oxalosis.

\section{Genotype-phenotype correlations}

Among the nine patients with PH1, five patients (Patients $1,3-5$, and 7) had truncating mutations in both alleles, and four patients (Patients 2, 6, 8, and 9) had one truncating mutation in one allele and one missense mutation in the other allele. All patients with two truncating mutations showed early onset ages ( $\leq 5$ months of age), whereas two of four patients with one truncating mutation showed older ages of onset at 2 years and 3 years, respectively. Retinal involvement indicating systemic oxalosis was detected in all patients with two truncating mutations, but in two of four patients with one truncating mutation. All patients with PH1 had ESRD at onset, except for Patient 9 who had one truncating mutation and presented with recurrent nephrolithiasis without renal functional impairment.

\section{Disease courses}

In four patients (Patients 1-3, and 7), pyridoxine therapy was initially started with dialysis, but was discontinued after the genetic diagnosis, which showed that their genotypes were expected to indicate pyridoxine non-responsiveness.

Among the eight $\mathrm{PH} 1$ patients who presented with ESRD,

Table 1. Genotypes of 11 Primary Hyperoxaluria Patients

\begin{tabular}{|c|c|c|c|}
\hline Patients & Genes & Mutation 1 & Mutation 2 \\
\hline 1 & AGXT & c.33dupC, p.Lys(AAG)12Gln(CAA)fs & c.577dupC, p.Leu(CTT)193Pro(CCT)fs \\
\hline 2 & AGXT & c.33delC, p.Lys(AAG)12Arg(AGG)fs*34 & c.335C>A, p.Ala(GCC)112Asp(GAC) \\
\hline 3 & AGXT & c.33dupC, p.Lys(AAG)12Gln(CAA)fs & Homozygote \\
\hline 4 & AGXT & c.33dupC, p.Lys(AAG)12Gln(CAA)fs & c.681-1G>A in intron $6 a$ \\
\hline 5 & AGXT & c.33dupC, p.Lys(AAG)12Gln(CAA)fs & Homozygote \\
\hline 6 & AGXT & c.33dupC, p.Lys(AAG)12GIn(CAA)fs & c.346G >C, p.Gly(GGG)116Arg(CGG) \\
\hline 7 & AGXT & c.331C>T, p.Arg(CGA)111*(TGA) & Homozygote \\
\hline 8 & AGXT & c.187G>C, p.Gly(GGC)63Arg(CGC) & c.823_824dupAG, p.Ser(AGC)275Arg(AGA)fs \\
\hline 9 & AGXT & c.33dupC, p.Lys(AAG)12Gln(CAA)fs & c.568G>A, p.Gly(GGG)190Arg(AGG) \\
\hline 10 & GRHPR & c.181G>A, p.Asp(GAC)61Asn(AAC)* & not detected \\
\hline 11 & HOGA1 & c.812G>A, p.Arg(CGC)271His(CAC)* & not detected \\
\hline
\end{tabular}

*novel mutations.

Table 2. Clinical Features of the Patients

\begin{tabular}{|c|c|c|c|c|c|c|c|c|c|}
\hline $\begin{array}{l}\text { Patient/ } \\
\text { Gender }\end{array}$ & GA/Birth weight & $\begin{array}{l}\text { Height/weight } \\
\text { percentile at Dx }\end{array}$ & $\begin{array}{l}\text { Age (months) } \\
\text { at onset/Dx }\end{array}$ & $\begin{array}{c}\text { Initial } \\
\text { presentation }\end{array}$ & $\begin{array}{l}\mathrm{NL} / \\
\mathrm{NC}\end{array}$ & $\begin{array}{l}\text { urinary } \mathrm{Ox} / \mathrm{Cr} \\
\text { (reference range) }\end{array}$ & $\begin{array}{c}\text { Initial } \\
\text { Scr/eGFR }\end{array}$ & $\begin{array}{l}\text { Retinal } \\
\text { lesion }\end{array}$ & $\begin{array}{c}\text { Disease course (ages [years] } \\
\text { at the last F-U) }\end{array}$ \\
\hline 1/male & 40 wks $/ 3.7 \mathrm{~kg}$ & $10-25 p / 10-25 p$ & $2 / 3$ & ESRD & $-/+$ & $544(<325-360)$ & $5.40 / 5.2$ & + & $\mathrm{PD} \rightarrow \mathrm{LT} \rightarrow$ death (0.5) \\
\hline 2/male & $39+6$ wks/3.24 kg & $10-25 p / 10-25 p$ & $4 / 4$ & ESRD & $-/+$ & $632(<325-360)$ & $3.45 / 8.2$ & - & $\mathrm{PD}+\mathrm{HD} \rightarrow \mathrm{LT} \rightarrow \mathrm{LT} \rightarrow \mathrm{HD}(7)$ \\
\hline 3/male & $40+2$ wks/3.36 kg & $25-50 p / 25-50 p$ & $3 / 3$ & ESRD & $-/+$ & $263(<325-360)$ & $6.27 / 4.4$ & + & $\mathrm{PD}+\mathrm{HD} \rightarrow \mathrm{LT} \rightarrow \mathrm{KT} \rightarrow \mathrm{eGFR} 32$ (6) \\
\hline 4/male & $40+5$ wks $/ 3.5 \mathrm{~kg}$ & 5-10p/5-10p & $2 / 3$ & ESRD & $-/+$ & $800(<325-360)$ & $5.74 / 4.5$ & + & $\mathrm{PD}+\mathrm{HD} \rightarrow \mathrm{LT} \rightarrow \mathrm{KT} \rightarrow \mathrm{eGFR} 90$ (6) \\
\hline 5/male & $39+5$ wks/2.9 6kg & $25-50 p / 10-25 p$ & $3 / 3$ & ESRD & $-/+$ & $161(<325-360)$ & $7.61 / 3.7$ & + & $\mathrm{PD}+\mathrm{HD} \rightarrow \mathrm{LT} \rightarrow \mathrm{KT} \rightarrow \mathrm{eGFR} 66$ (5) \\
\hline 6/male & Fullterm $/ 3 \mathrm{~kg}$ & $10-25 p / 10-25 p$ & $36 / 118$ & ESRD & $+/+$ & n. c. & $9.8 / 9.1$ & + & $\mathrm{HD} \rightarrow \mathrm{PD}(16)$ \\
\hline 7/female & $40 \mathrm{wks} / 2.78 \mathrm{~kg}$ & $10-25 p / 25 p$ & $5 / 5$ & ESRD & $+/+$ & n. c. & $6.19 / 4.0$ & - & $\mathrm{PD}+\mathrm{HD} \rightarrow \mathrm{PD}(0.6)$ \\
\hline 8/male & $37+6$ wks/2.97 kg & $10-25 p / 25-50 p$ & $2 / 2$ & ESRD & $-/+$ & $540(<325-360)$ & $3.78 / 8.2$ & + & $\mathrm{HD}(0.3)$ \\
\hline 9/male & Fullterm/3.34 kg & $15-25 p / 25-50 p$ & $25 / 61$ & $\mathrm{NL}$ & $+/-$ & $292(<70-82)$ & $0.46 / 104.9$ & n. c. & eGFR 103 (8) \\
\hline 10/male & Fullterm/2.9 kg & $10-15 p / 10-15 p$ & $23 / 34$ & GHU, NL & $+/+$ & $824(<98-101)$ & $0.35 / 111$ & n. c. & eGFR 105 (5) \\
\hline 11/male & 27 wks/1.08 kg & $<3 p /<3 p$ & $2 / 4$ & $\mathrm{NL}$ & $+/+$ & $2845(<325-360)$ & $0.17 / 130$ & - & eGFR 123 (2) \\
\hline
\end{tabular}

GA, gestational age; Dx, diagnosis; eGFR, estimated glomerular filtration rate calculated using the Schwartz formula $(\mathrm{ml} / \mathrm{min} / 1.73 \mathrm{~m})^{2}$; ESRD, end-stage renal disease; F-U, follow-up; GHU, gross hematuria; HD, hemodialysis; PD, peritoneal dialysis; RRT, renal replacement therapy; KT, kidney transplantation; LT, liver transplantation; NL, nephrolithiasis; NC, nephrocalcinosis; n.c., not checked; Ox/Cr, oxalate to creatinine ratio (mmol/mol) in spot urine; Scr, serum creatinine $(\mathrm{mg} / \mathrm{dL})$. 
five patients were initially treated with combined hemodialysis and nocturnal peritoneal dialysis to maximize oxalate removal, and three patients were treated with hemodialysis or peritoneal dialysis. Later, five patients (Patients 15) underwent liver transplantation with/without subsequent kidney transplantation $(n=3)$. Patient 1 underwent deceaseddonor liver transplantation at the age of 4 months. However, he developed fulminant sepsis due to surgical wound problems and died on the $51^{\text {st }}$ postoperative day. Patient 2 underwent deceased-donor liver transplantation at the age
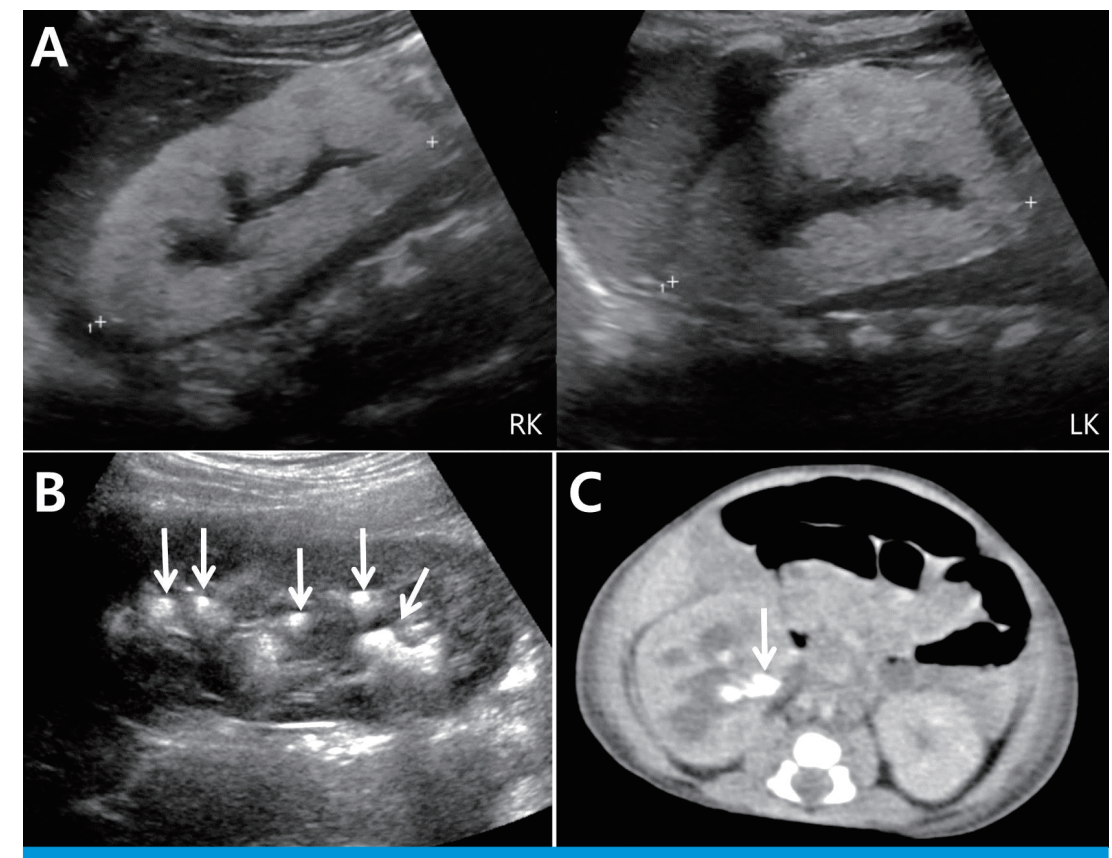

Fig. 1. Imaging studies in patients with primary hyperoxaluria. (A) Kidney ultrasonography shows diffuse increased echogenicity indicating nephrocalcinosis and loss of corticomedullary differentiation of both kidneys in patient 1. (B) Kidney ultrasonography shows multiple stones (arrows) in patient 9. (C) Abdomen CT scan shows a staghorn stone (arrow) with hydronephrosis in the right kidney of patient 11.

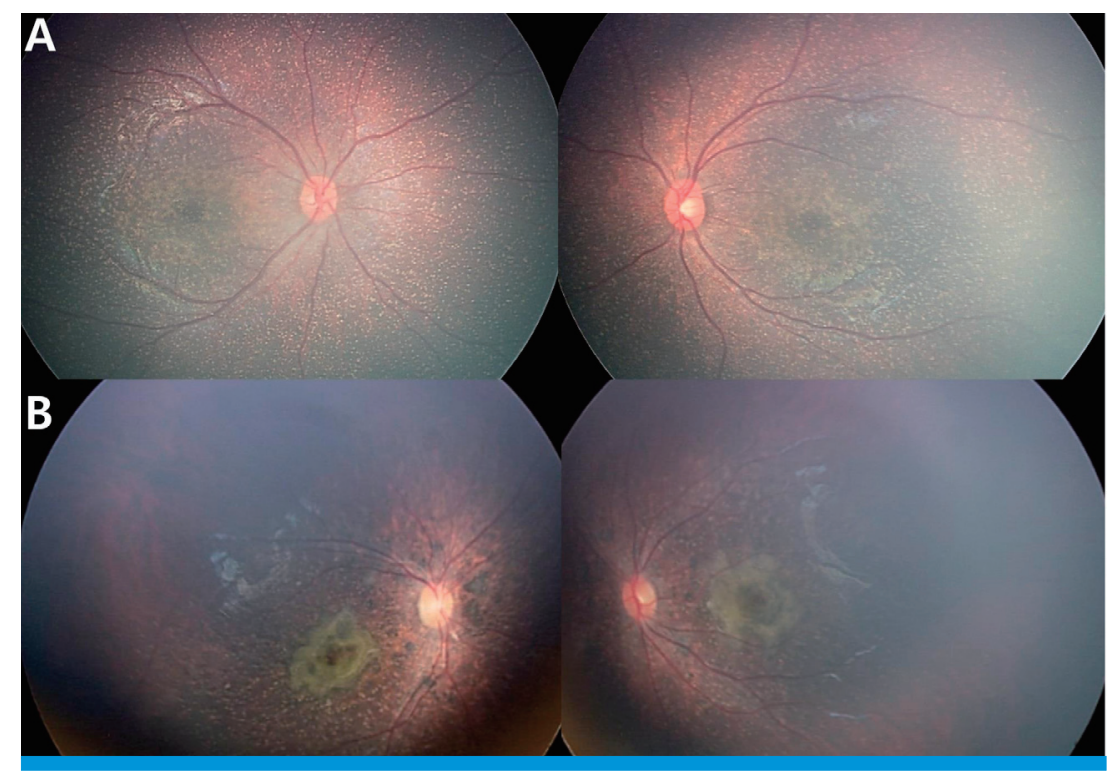

Fig. 2. Retina of primary hyperoxaluria patients indicating systemic oxalosis. (A) Calcium oxalate crystal deposition in patient 1. B) Central geographic macular lesion surrounded by flecks in patient 2 . 
of 6 years but developed primary graft non-function. He received a second liver transplantation from his mother soon thereafter. He is currently waiting for kidney transplantation while on hemodialysis. Patient 3 received deceased-donor liver transplantation at the age of 3 years followed by a living-donor kidney transplantation from his mother 3 months later. However, the graft kidney was lost due to primary graft non-function and again underwent a second kidney transplantation from a deceaseddonor. Currently, he has chronic kidney disease (CKD) stage 3 without dialysis. Patient 4 received deceased-donor liver transplantation at the age of 1 year followed by a deceased-donor kidney transplantation at the age of 5 years. Currently, his estimated glomerular filtration rate (eGFR calculated using the Schwartz formula) is $90.3 \mathrm{ml} / \mathrm{min} / 1.73$ $\mathrm{m}^{2}$. Patient 5 received deceased-donor liver transplantation followed by a deceased-donor kidney transplantation at the age of 6 months and 2 years, respectively. Currently, he has CKD stage 2. Among the remaining four patients with $\mathrm{PH} 1$, three patients (Patients 6-8) are waiting for organ transplantation while on dialysis. Patient 9 maintains normal renal function although he had recurrent episodes of nephrolithiasis despite oral potassium citrate medication.

Patient 10 with non-PH1 presented with gross hematuria on the diaper at the age of 2 years. Kidney ultrasonography showed medullary nephrocalcinosis with multiple renal stones. He was prescribed high fluid intake and oral potassium citrate, and the latest kidney ultrasonography showed persistent medullary nephrocalcinosis without recurrence of nephrolithiasis. Patient 11 with non-PH1 presented with a staghorn stone in the right kidney with hydrouretronephrosis. He underwent percutaneous nephrostomy, and chemical analysis revealed that the stone was composed of $80 \%$ calcium oxalate, $10 \%$ carbonate apatite, and $10 \%$ struvite. Nephrolithiasis did not recur on oral potassium citrate medication and his renal function is maintained normally.

\section{Discussion}

This study showed a case series of 11 Korean pediatric cases, including nine cases with a genetic diagnosis of PH1. The estimated prevalence of $\mathrm{PH} 1$ has been reported to be
1-3 per million populations in Europe, 8,9 and $\mathrm{PH} 1$ accounts for $0.5-2 \%$ of pediatric ESRD in Europe, North America, and $\operatorname{Japan}^{10-12)}$. The prevalence of $\mathrm{PH} 1$ is higher in Mediterranean consanguineous populations, and the proportion of $\mathrm{PH} 1$ as a cause of pediatric ESRD is $10 \%$ in Kuwait ${ }^{13)}$ and $13 \%$ in Tunisia ${ }^{14)}$. There have been no data on large cohorts except a few case reports of PH in Korea so $\mathrm{far}^{6,7)}$. Although we did not analyze the prevalence of $\mathrm{PH}$, given that the patients in our study were limited to pediatric cases from three tertiary centers in Korea with a total population of approximately 50 million, the prevalence of PH1 in Korea might be similar to that in Western countries. In addition, $\mathrm{PH} 1$ accounts for $0.9 \%$ of pediatric ESRD according to the data of the chronic kidney disease registry of the Korean Society of Pediatric Nephrology (not published data). The marked male preponderance in our study is not explained.

In our study, 10 different $A G X T$ mutations were detected, including a novel mutation, c.681-1G $>\mathrm{A}$ in intron 6. The GRHPR mutation (c.181G >A, p.Asp61Asn, rs371660673) detected in Patient 10 was predicted to be disease-causing by MutationTaster (http://www.mutationtaster.org/), and the minor allele frequency was reported to be $0.00005 / 6$ on ExAC Browser (http://exac.broadinstitute.org/), 0.00008/1 on GO-ESP (http://evs.gs.washington.edu/EVS/), and 0.000008/1 on TOPMED (https://www.nhlbi.nih.gov/ science/trans-omics-precision-medicine-topmed-program). The HOGA1 mutation (c.812G>A, p.Arg271His) detected in Patient 11 was also predicted to be diseasecausing by MutationTaster, and the minor allele frequency was reported to be 2/7524 in East Asians and 4/103800 in the total population on the ExAC Browser. However, a genetic diagnosis of Patients 10 and 11 was not confirmed because they only carried a single heterozygous mutation.

The most commonly detected $A G X T$ mutation in our study was c.33dupC mutation with an allelic frequency of $44 \%$. The run of eight cytosine residues (c.26_33) in exon 1 is known to be particularly prone to deletion/insertion mutations. Accordingly, c.33dupC mutation has been known as one of the three most common mutations across populations, p.Gly170Arg, c.33dupC, and p.Ile244Thr. However, the allele frequency of the c.33dupC mutation in our study was much higher than that in other studies (11$15 \%$ of total $A G X T$ mutant alleles) ${ }^{15,16)}$. In addition, the $\mathrm{p}$. 
Gly170Arg mutation, which is the most common mutation occurring at a frequency of approximately $30 \%{ }^{15,16)}$ and shows responsiveness to pyridoxine ${ }^{17,18)}$, was not detected in our study.

Several studies have reported the possible association of homozygous c.33dupC mutation with poor prognosis, including earlier onset and more rapid progression to ESRD, in accordance with the complete lack of AGT protein ${ }^{15,18-20)}$. However, there is a marked intra- and inter-familial phenotypic heterogeneity in families with homozygous c.33dupC mutation from ESRD in infancy to PH diagnosed in the second or third decade of life ${ }^{21,22)}$. In our study, although the number of total patients was too small, patients with two truncating mutations including c.33dupC mutation, showed earlier ages of onset and more frequent retinal involvement than patients with one truncating mutation.

There has been no clear genotype-phenotype correlation in $\mathrm{PH} 1$, except for pyridoxine responsiveness in some patients with PH1, particularly in those with homozygous p.Gly170Arg or Phe152Ile mutations ${ }^{17,19)}$. Pyridoxine, vitamin B6, is a known cofactor of AGT and is effective in reducing urine oxalate excretion in about a third of $\mathrm{PH} 1$ patients ${ }^{23)}$. Unfortunately, none of the patients in our study had p.Gly170Arg or p.Phe152Ile mutations.

Renal damage is inevitable in most patients with PH1 and ultimately progresses to ESRD. When the GFR drops to $30-45 \mathrm{~mL} / \mathrm{min} / 1.73 \mathrm{~m}^{2}$, the kidney is unable to excrete the oxalate load effectively and oxalate is subsequently deposited in all tissues (systemic oxalosis) ${ }^{24}$. Since conventional hemodialysis and peritoneal dialysis do not eliminate sufficient amounts of oxalate, more intensive strategies such as short daily sessions of high-flux dialysis, nocturnal dialysis, or combinations of hemodialysis and nocturnal peritoneal dialysis, must be used to avert a continuous positive balance of oxalate and to limit systemic oxalosis ${ }^{25}$. For patients before reaching CKD stage 4, preemptive liver transplantation to avoid the complications of systemic oxalosis would be a logical approach ${ }^{26)}$. However, this approach raises ethical issues given the risk of graft failure and death associated with the procedure ${ }^{27)}$. Isolated kidney transplantation to correct ESRD in PH1 is frequently followed by recurrence of the disease in the graft kidney since the liver is the site of the metabolic defect. Therefore, combined liver and kidney transplantation is a reasonable choice for these patients, although kidney transplantation alone may be considered on an individual basis such as in adults with confirmed responsiveness to pyridoxine $e^{1,10)}$. While dual transplantation is a reasonable choice for patients with CKD stage 4, sequential liver and kidney transplantation for patients with CKD stage 5 has the advantage that it provides sufficient time for the use of aggressive dialysis, which may mobilize some of the systemic oxalate burden and protect the kidney to be transplanted subsequently ${ }^{1,28,29)}$. In our study, we adopted sequential liver and kidney transplantation for eight patients presenting with ESRD: three patients have already undergone this procedure and the rest are waiting for organ donation. According to the European pediatric registry ${ }^{10)}$, the 5-year survival rate for kidney transplantation alone and dual kidney and liver transplantation in children with $\mathrm{PH}$ was $14 \%$ and 76 $\%$, respectively

There is a limited experience with organ transplantation in patients with $\mathrm{PH} 2$. Although the ubiquitous tissue distribution of GRHPR favors kidney transplantation, some transplant recipients have undergone oxalate-related graft loss ${ }^{5}$. PH3 has not been associated with ESRD thus far, but there have been a couple of cases with impaired renal function ${ }^{30)}$.

In conclusion, the estimated prevalence of $\mathrm{PH} 1$ in Korea was similar to that reported in other studies from Europe, North America, and Japan. The c.33dupC was the most common AGXT mutation with an allelic frequency of $44 \%$. The median age of onset was 3 months, and eight patients with PH1 already had ESRD at initial presentation. Although the number of total patients was too small, patients with two truncating mutations showed earlier ages of onset and more frequent retinal involvement than patients with one truncating mutation. Sequential liver and kidney transplantation was adopted for $\mathrm{PH} 1$ patients presenting with ESRD. A major limitation of this study was the small number of subjects. Therefore, a larger, nation-wide, multicenter study is needed.

\section{Author Contributions}

Conceptualization: Cheong HI. Methodology: Choe Y, Kim JH, Lee JH, Park YS, Kang HG, Ha IS. Formal analysis: 
Choe Y, Lee JM, Kim JH, Kim SH, Lee JH, Kang HG. Data curation: Lee JM, Cho MH, Park YS. Validation: Cho MH, Kim SH, Park YS, Ha IS, Cheong HI. Investigation: Kim $\mathrm{JH}$, Cho MH, Cheong HI. Writing - original draft preparation: Choe Y, Lee JM. Writing - review and editing: Kim SH, Lee JH, Park YS, Kang HG, Ha IS, Cheong HI. Approval of final manuscript: all authors.

\section{ORCID}

Yunsoo Choe https://orcid.org/0000-0001-9396-1676 Jiwon M. Lee https://orcid.org/0000-0003-3932-614X Ji Hyun Kim https://orcid.org/0000-0001-8477-0157 Myung Hyun Cho https://orcid.org/0000-0002-3237-3173 Seong Heon Kim https://orcid.org/0000-0001-8003-3010 Joo Hoon Lee https://orcid.org/0000-0001-8010-3605 Young Seo Park https://orcid.org/0000-0001-7653-2036 Hee Gyung Kang https://orcid.org/0000-0001-8323-5320 Il-Soo Ha https://orcid.org/0000-0001-5428-6209 Hae Il Cheong https://orcid.org/0000-0001-7556-1265

\section{Patient consent}

This study was approved by the institutional review board (IRB), and the consent was waived due to the nature of the retrospective study [IRB number 1812-002-264].

\section{Acknowledgments}

This research was supported by the Korea Health Technology R\&D Project through the Korea Health Industry Development Institute (KHIDI), funded by the Ministry of Health \& Welfare, Republic of Korea (grant number : HI18C0013).

\section{Conflicts of interest}

No potential conflict of interest relevant to this article was reported.

\section{References}

1. Cochat P, Rumsby G. Primary hyperoxaluria. N Engl J Med 2013; 369:649-58.

2. Purdue PE, Takada Y, Danpure CJ. Identification of mutations associated with peroxisome-to-mitochondrion mistargeting of alanine/glyoxylate aminotransferase in primary hyperoxaluria type 1. J Cell Biol 1990;111(6 Pt 1):2341-51.

3. Cramer SD, Ferree PM, Lin K, Milliner DS, Holmes RP. The gene encoding hydroxypyruvate reductase (GRHPR) is mutated in patients with primary hyperoxaluria type II. Hum Mol Genet 1999;8:2063-9.

4. Belostotsky R, Seboun E, Idelson GH, Milliner DS, Becker-Cohen $R$, Rinat $C$, et al. Mutations in DHDPSL are responsible for primary hyperoxaluria type III. Am J Hum Genet 2010;87:392-9.

5. Hoppe B. An update on primary hyperoxaluria. Nat Rev Nephrol 2012;8:467-75.

6. Kim HH, Koh HI, Ku BI, Lee HS. Late-onset primary hyperoxaluria diagnosed after renal transplantation presented with early recurrence of disease. Nephrol Dial Transplant 2005;20:1738-40.

7. Kim SE, Kim SJ, Chu ST, Yang SH, Kim YS, Cha RH. A rare case of hyperoxaluria presenting with acute liver injury and stone-free kidney injury. Kidney Res Clin Pract 2015;34:113-6.

8. Cochat P, Deloraine A, Rotily M, Olive F, Liponski I, Deries N. Epidemiology of primary hyperoxaluria type 1. Nephrol Dial Transplant 1995;10 Suppl 8:3-7.

9. van Woerden CS, Groothoff JW, Wanders RJ, Davin JC, Wijburg FA. Primary hyperoxaluria type 1 in the Netherlands: prevalence and outcome. Nephrol Dial Transplant 2003;18:273-9.

10. Harambat J, van Stralen KJ, Espinosa L, Groothoff JW, Hulton SA, Cerkauskiene R, et al. Characteristics and outcomes of children with primary oxalosis requiring renal replacement therapy. Clin J Am Soc Nephrol 2012;7:458-65.

11. North American Pediatric Renal Trials and Collaborative Studies. NAPRTCS 2011 Annual Dialysis Report. https://web.emmes. com/study/ped/annlrept/annualrept2011.pdf.

12. Hattori S, Yosioka K, Honda M, Ito H. Japanese Society for Pediatric Nephrology. The 1998 report of the Japanese national registry data on pediatric end-stage renal disease patients. Pediatr Nephrol 2002;17:456-61.

13. Al-Eisa AA, Samhan M, Naseef M. End-stage renal disease in Kuwaiti children: an 8-year experience. Transplant Proc 2004;36: 1788-91.

14. Kamoun A, Lakhoua R. End-stage renal disease of the Tunisian child: epidemiology, etiologies, and outcome. Pediatr Nephrol 1996;10:479-82.

15. Williams EL, Acquaviva C, Amoroso A, Chevalier F, Coulter-Mackie M, Monico CG, et al. Primary hyperoxaluria type 1: update and additional mutation analysis of the AGXT gene. Hum Mutat 2009;30:910-7.

16. Hopp K, Cogal AG, Bergstralh EJ, Seide BM, Olson JB, Meek AM, 
et al. Rare Kidney Stone Consortium. Phenotype-genotype correlations and estimated carrier frequencies of primary hyperoxaluria. J Am Soc Nephrol 2015;26:2559-70.

17. Monico CG, Rossetti S, Olson JB, Milliner DS. Pyridoxine effect in type I primary hyperoxaluria is associated with the most common mutant allele. Kidney Int 2005;67:1704-9.

18. Harambat J, Fargue S, Acquaviva C, Gagnadoux MF, Janssen F, Liutkus A, et al. Genotype-phenotype correlation in primary hyperoxaluria type 1: the p.Gly170Arg AGXT mutation is associated with a better outcome. Kidney Int 2010;77:443-9.

19. van Woerden CS, Groothoff JW, Wijburg FA, Annink C, Wanders RJ, Waterham HR. OxalEurope Consortium. Clinical implications of mutation analysis in primary hyperoxaluria type 1. Kidney Int 2004;66:746-52.

20. Mandrile G, van Woerden CS, Berchialla P, Beck BB, Acquaviva Bourdain C, Hulton SA, et al. Data from a large European study indicate that the outcome of primary hyperoxaluria type $1 \mathrm{cor}$ relates with the AGXT mutation type. Kidney Int 2014;86:1197-204.

21. Rumsby G, Williams E, Coulter-Mackie M. Evaluation of mutation screening as a first line test for the diagnosis of the primary hyperoxalurias. Kidney Int 2004;66:959-63.

22. Frishberg Y, Rinat C, Shalata A, Khatib I, Feinstein S, Becker-Cohen $R$, et al. Intra-familial clinical heterogeneity: absence of genotype-phenotype correlation in primary hyperoxaluria type 1 in Israel. Am J Nephrol 2005;25:269-75.

23. Milliner DS, Eickholt JT, Bergstralh EJ, Wilson DM, Smith LH. Results of long-term treatment with orthophosphate and pyrido- xine in patients with primary hyperoxaluria. N Engl J Med 1994; 331:1553-8

24. Hoppe B, Kemper MJ, Bökenkamp A, Portale AA, Cohn RA, Langman CB. Plasma calcium oxalate supersaturation in children with primary hyperoxaluria and end-stage renal failure. Kidney Int 1999;56:268-74.

25. Illies F, Bonzel KE, Wingen AM, Latta K, Hoyer PF. Clearance and removal of oxalate in children on intensified dialysis for primary hyperoxaluria type 1. Kidney Int 2006;70:1642-8.

26. Kemper MJ, Nolkemper D, Rogiers X, Timmermann K, Sturm E, Malago $M$, et al. Preemptive liver transplantation in primary hyperoxaluria type 1: timing and preliminary results. J Nephrol 1998;11 Suppl 1:46-8.

27. Cochat P, Groothoff J. Primary hyperoxaluria type 1: practical and ethical issues. Pediatr Nephrol 2013;28:2273-81.

28. Malla I, Lysy PA, Godefroid N, Smets F, Malaise J, Reding R, et al. Two-step transplantation for primary hyperoxaluria: cadaveric liver followed by living donor related kidney transplantation. Pediatr Transplant 2009;13:782-4.

29. Mor E, Nesher E, Ben-Ari Z, Weissman I, Shaharabani E, Eizner S, et al. Sequential liver and kidney transplantation from a single living donor in two young adults with primary hyperoxaluria type 1. Liver Transpl 2013;19:646-8.

30. Allard L, Cochat P, Leclerc AL, Cachat F, Fichtner C, De Souza VC, et al. Renal function can be impaired in children with primary hyperoxaluria type 3. Pediatr Nephrol 2015;30:1807-13. 